www.jmscr.igmpublication.org

Impact Factor 5.244

Index Copernicus Value: 83.27

ISSN (e)-2347-176x ISSN (p) 2455-0450

crossref DOI: _https://dx.doi.org/10.18535/jmscr/v4i10.121

Journal Of Medical Science And Clinical Research

IGM Publication

An Official Publication of IGM Publication

\title{
The Analysis of the outcome with High Dose Rate (H.D.R) Brachytherapy in Oropharyngeal Cancers Either Alone or with External Beam Radiotherapy (EBRT)
}

Authors

\section{Dr C.S.K. Prakash, M.D (R.T) ${ }^{1}$, Dr Kamreddy Ashok Reddy, M.S (ENT) ${ }^{2}$, Dr Lakkaraju Ravindra Babu, B.D. $\mathbf{S}^{3}$}

${ }^{1}$ Associate Professor, Department of Radiotherapy, Kakatiya Medical College and Mahatma Gandhi Memorial Hospital, Warangal, 506007 India

${ }^{2}$ Assistant Professor, Department of ENT, and Mahatma Gandhi Memorial Hospital \& Kakatiya Medical College, Warangal, 506007 India

${ }^{3}$ Post Graduate Student, Department of Periodontics, Kamineni Institute Of Dental Sciences, Narketpally508 254. Dental Assistant Surgeon, Govt. of Telangana Health Services

Corresponding Author

Dr Chennapragada Sri Krishna Prakash M.D (R.T)

H/O Dr.N.Madhavi, Plot No. 44, $3^{\text {rd }}$ Floor, Road No 4b, Mamatha Nagar, Old Nagole, Hyderabad -500 068. Email: csk_prakash@hotmail.com,srikrishnaprakash@yahoo.co.in Ph.no: +919848006075

\begin{abstract}
Purpose: We analysed the results of 34 patients of oropharyngeal carcinomas treated with HDR brachytherapy alone or with EBRT Patients and Methods: The outcome of patients treated with oropharyngeal cancers treated with HDR interstitial or mould brachytherapy alone or with EBRT were analysed. The patients underwent treatment between 2004and 2009 at M.N.J. Institute of Oncology and Regional Cancer Centre, Hyderabad. The minimum follow up period was 24 months.

Patients with T1, T2 lesions received EBRT 50Gy. T3 lesions had 56Gy and T4 lesions had 60 Gy. Patients with residual neck nodes had 10Gy of additional electron boost. Patients having no palpable neck nodes had interstitial brachytherapy. For all patients 3 Gy per fraction, for 5-6 fractions, with 2 fractions per day with minimum interval between two fractions was 6 hours. The first and the last fraction the dose of $4 G y$ was administered instead of $3 G y$. Six patients with carcinoma hard palate were treated with HDR mould brachytherapy with 42-45Gy/14-15Fractions. The outcome was analysed.

Results: Patients with T1 and T2 lesions 90\%patients, while 78.57\%) T3, T4 lesions had no evidence of recurrence and none of the patients with T1, T2 developed complications and $7.14 \%$ of T3, T4 patients had complications like necrosis or necrosis and fistulae. Patients with T1NOMO hard palate carcinomas, treated by mould brachytherapy had 100\% local control rates and 0\% long term complications of radiotherapy.

Conclusion: Oropharyngeal carcinomas can be best treated with combination of EBRT and HDR brachytherapy. Hard palate TINOMO lesions can be best treated by HDR mould brachytherapy, thereby reducing overall treatment time and complications.

Keywords: Oropharyngeal carcinomas and High Dose Rate (HDR) brachytherapy.
\end{abstract}




\section{Introduction}

Early stages the head and neck cancers can be treated by surgery or radiotherapy with equal results. Surgery will be in the form of wide local excision without much cosmetic abnormalities and loss of function in early stages ${ }^{1,2}$ and 3 . Majority of the head and neck cancers were in advanced stage at presentation and surgery will be mutilating and all the patients require post-operative radiotherapy. Concurrent chemo radiotherapy will provide equivalent response rates with surgery followed by External Beam Radiotherapy(EBRT).

Brachytherapy can be used alone or as a boost to the tumor volume as an adjuvant to EBRT plays a key role in the management of head and neck cancers. Majority sites of head and neck cancers can be treated by brachytherapy. Main aim of cancer treatment is to deliver maximum tumor dose and at the same time respecting the surrounding normal structures. This can be best achieved by brachytherapy, where we can achieve better tumor control as the radiation source will be nearer to tumor and minimizing damage to normal surrounding tissues by rapid fall off of dose $e^{4,5}$.

Radioactive isotopes like 198, Iodine 125 and Palladium 103can be used as permanent implants in various head and neck sites like tonsil, tongue, cervical lymph nodes and nasopharynx were well described both for primary and recurrent carcinomas.

High Dose Rate (HDR) remote after loading sources were now used in most parts of India using Iridium (Ir) 192 or with Cobalt (Co) 60 source, which were gamma ray emitters

HDR brachytherapy can be carried out in head and neck cancers by interstitial implants, Intracavitary andsurface mould application.

Removable Interstitial implantation is carried out by inserting flexible plastic implant tubes into various sites like tongue, base of tongue, faucial pillars, soft pate and pharyngeal walls ${ }^{3}$. Intracavitary brachytherapy (or Intra luminal brachytherapy) can be carried out with various applicators in nasopharyngeal carcinoma, nasal cavity. Surface mould brachytherapy can be carried out with custom made surface applicators with radioactive source flexible catheters placed apart $^{6}$.

Now a days, the present HDR brachytherapy machine using a source usually a sourceusually Iridium (Ir) 192 with few mm length and $<1 \mathrm{~mm}$ diameter and with high activity ${ }^{7}$.

High Dose Rate (HDR) brachytherapy equipment were accompanied by Treatment Planning System (TPS), calculation of dose distribution and optimization for individual cases ${ }^{8,9 a n d 10}$. There by quality assurance and precision planning.

Computerized treatment planning system and optimization provides accurate dose distribution details and the radiation exposure is minimized by remote after loading device ${ }^{7,8,9}$ and 10.

In the present study, we analysed the treatment outcome of the patients who were treated by brachytherapy alone or in combination with EBRT in oropharyngeal carcinomas.

\section{Patients and Methods}

In the present study, we analysed treatment results of total number of 32 patients with oropharyngeal carcinomas treated by Interstitial and Surface Mould brachytherapy alone or in combination with EBRT, carried out between 2004-2009 at M.N.J.Institute of Oncology \& RCC, Redhills, Hyderabad, India with minimum follow up period of 48 months and the results were analysed.

Before starting treatment, all the patients underwentpre-treatment evaluation, which consist of detail history and physical examination, biopsy. Patients with base of tongue and tonsillarcarcinomas, underwent complete ENT evaluation including DLS/IDL/ video laryngoscopy to know the lower extent of the disease. All the Patients underwent pre-treatment base line complete blood picture, renal function tests, liver function tests including serum alkaline phosphatase examination, chest $\mathrm{x}$ ray, ultrasound abdomen and pelvis. The patients underwent CECT head and neck and if any suspicious lesions were found on chest $\mathrm{x}$ ray and ultra sound abdomen, CECT of chest, abdomen was done. Pre-treatment dental 
evaluation, including pre radiotherapy dental prophylaxis and extractions were done. Mandatory rest periodwas given before starting EBRT in patients who underwent pre EBRT dental extraction. All the patients were staged according to American Joint Committee on Cancer Staging Classification $1992^{18}$. All the patients with metastatic disease were excluded from this study. Patients who underwent previous radiotherapy were not considered for brachytherapy.

\section{For Patients with HDR Mould Brachytherapy:}

Whereas patients with $\mathrm{T} 1$ hard palate lesions without clinically and radiologically palpable nodes, HDR Mould Brachytherapy was planned.

individual's Hard Palate impression was prepared with Dental Moulding Material for each patient. Tumor was traced on the Mould. HDR source catheters are placed at 0.8 to $1 \mathrm{~cm}$ apart based on the tumor size and with treatment margin in the grooves made manually and the flexible interstitial brachytherapy catheters were fixed in the grooves, which were parallel to each other. Before and after placing the catheters, dummy source checks were carried out to know the patency of the catheters. Dental Mould with catheters are covered with dental wax to reduce discomfort to the patient. There is problem with incisor teeth and anterior palate causing some areas of irregularity of the arch of the surface, leading to smaller diameter tubes so as to pass the source to pass through the tubes. This will lead to a gap between channels and surface of the moulds. The patients were simulated with intraoral wax mould and with dummy sources. Target volume is defined. Treatment Planning and optimization was done with Plato treatment planning system. The patients were treated with a total dose of 42-45Gy/14-15 Fractions, with 3 Gy per fractions with 2 fractions per day with minimum interval between two fractions was 6 hours. The Severity of Oral mucosal reactions were recorded during treatment and after completion of treatment. During Radiotherapy, patients were kept on mouth gargles and prophylactic oral antifungal. During treatment, patients who were experiencing pain due to mucosal reactions were given xylocaine spray five to ten minutes before placing mould. The minimum follow up period was two years and maximum follow up period was five years.

The patients received External Beam Radiotherapy (EBRT) as primary modality of treatment. The irradiation was carried out with megavoltage equipment with Cobalt 60 equipment. Once Multi energy Linac was available, the patients were treated with appropriate energy. For residual neck nodes, electron boost was administered.

Immobilization was done for all patients (both groups of patients) with head and neck thermoplastic masks in supine position and all patients were simulated with immobilization mask. Two lateral parallel opposed fields were used to cover the primary tumor and upper neck nodes. A lower anterior field was added to cover lower neck up to supraclavicular area...Laryngeal shielding was done in all patients. The treatment was carried out up to $44-46$ Gy in this $1^{\text {st }}$ phase. In the second phase, spinal cord sparing was done and EBRT was extended up to 50-60 Gy based on the stage of the tumor. For oropharyngeal carcinomas except for hard palate lesions, $50 \mathrm{~Gy}$ of EBRT for T1, T2 lesions and $56 \mathrm{~Gy}$ for T3 lesions and $60 \mathrm{~Gy}$ for $\mathrm{T} 4$ lesions were administered. Patients with residual neck nodes received electron boost of 10 Gy to neck node. Patients with tumor invading or immediately adjacent to bone were not considered for brachytherapy.

All the patients received conventional Radiotherapy 50-66 Gy of EBRT, 200cGy per fraction, 5 fractions per week. Stage III and Stage IV disease patients received concurrent chemotherapy with Inj. Cisplatin $40 \mathrm{mg} / \mathrm{m} 2$ weekly during EBRT...

Before brachytherapy, review of history and physical examination, and ENT re-evaluations were carried out to know the air way status. Informed consent was taken and the procedure was explained to the patient

For Patients with Interstitial Implant brachytherapy: All the Patients underwent 
implantation 2 weeks after the completion of EBRT. Underwent procedure once they got anaesthetic clearance and 15 days after pre EBRT dental prophylaxis. Patients were implanted undergeneral anaesthesia with endonasal intubation. Clinical Target Volume (CTV) is delineated based on pre EBRT and chemotherapy clinical, radiological and endoscopy findings and radiopaque markers were placed. Brachytherapy catheters were placed at $1.5-2 \mathrm{~cm}$ equidistance, parallel to each other ${ }^{(20)}$. When the tumor is on the surface, where loops are required 2 buttons or $1 \mathrm{~cm}$ piece soft paediatric nasogastric tube were placed on the surface(example tongue ca) or the simplified non looping functional loop technique as described by Subir Nag, Elmer R. Cano et al ${ }^{(21)}$ was practised. The patients were simulated with dummy sources.Target volume is defined. Treatment Planning and optimization was done with plato treatment planning system. For all patients 3 Gy per fraction, for 5-6 fractions, with 2 fractions per day with minimum interval between two fractions was 6 hours. The first and the last fraction the dose of $4 \mathrm{~Gy}$ was administered instead of 3Gy. All the patients had Naso Gastric (NG) tube insertion during procedure andfeeding was continued till mucosal reactions subside.

\section{Results}

Total number of 34 patients with oropharyngeal cancers were treated with HDR brachytherapy. Out of which $58.82 \%$ (20/34) of patients had T1, T2 lesions and $41.18 \%$ (14/34) of patients were of T3 and T4. Out of 34 patients, 28 patients had interstitial implantation brachytherapy after EBRT as per our treatment protocol. Six out of 34 patients were early carcinoma of the hard palate region (T1N0M0), who had HDR Mould brachytherapy alone (Table 1).

After the completion of procedure, we evaluated the patients for local recurrence and delayed radiation sequelae according to $\mathrm{T}$ stage. Patients with T1 and T2 lesions 18 out of 20 (90\%) patients had no evidence of recurrence and none of the patients developed complications like necrosis or necrosis and fistulae (Table 2).

The patients with T3,T4 lesions, 11 out of 14 (78.57\%) had no evidence of local recurrence during their follow up period and one patient with base of tongue carcinoma had complications necrosis and fistula (table 3 ).

A total of 6 patients were studied, age of these patients ranged between 50 to 70 years. All of them had T1 lesions as per the inclusion criteria. One each patient had squamous cell carcinoma with histopathological grade 2 lesion and grade 3 lesion while the remaining four patients had grade 1 lesion. These patients were followed for 3-5 years and complete remission was seen in all the cases. All the patients received radiation dose of 3 Grays per fraction with 2 fractions per day with minimum 6 hours interval for 14 to 15 fractions over a period of 10 to 14 days. None of the patients had recurrence during the follow up period. We produced an acceptable plan for all the six patients. The variation in the surface of lesions and variation in implant distance leads to generate a plan which delivers uniform dose to the whole area (Table 4)

Table 1. Summary Of Site Wise Involvement

\begin{tabular}{|l|l|l|l|}
\hline A.INTERSTITIAL BRACHYTHERAPY & T1/T2 & T3/T4 & Total \\
\hline SITE & 1 & 3 & 4 \\
\hline LIP & 3 & 4 & 7 \\
\hline MOBILE TONGUE & 2 & - & 2 \\
\hline BUCCAL MUCOSA & 5 & 3 & 8 \\
\hline FLOOR OF MOUTH & 2 & 1 & 3 \\
\hline TONSILLAR FOSSA & 1 & 3 & 4 \\
\hline BASE OF TONGUE & \multicolumn{5}{l|}{} \\
\hline B. MOULD BRACHYTHERAPY & 6 & 0 & 6 \\
\hline HARD PALATE & 6 & 14 & 34 \\
\hline ALL SITES(TOTAL) & 20 &
\end{tabular}


Table 2, T1,T2 Lesions Treated By HDR Brachytherapy.

\begin{tabular}{|l|l|l|l|}
\hline A.INTERSTITIAL BRACHYTHERAPY & $\begin{array}{l}\text { WITHOUT } \\
\text { LOCAL } \\
\text { RECURRENCE }\end{array}$ & NECROSIS & $\begin{array}{l}\text { NECROSIS } \\
\text { AND } \\
\text { FISTULA }\end{array}$ \\
\cline { 2 - 4 } & $1 / 1$ & 0 & 0 \\
\hline LIP & $3 / 3$ & 0 & 0 \\
\hline MOBILE TONGUE & $2 / 2$ & 0 & 0 \\
\hline BUCCAL MUCOSA & $4 / 5$ & 0 & 0 \\
\hline FLOOR OF MOUTH & $1 / 2$ & 0 & 0 \\
\hline TONSILLAR FOSSA & $1 / 1$ & 0 & 0 \\
\hline BASE OF TONGUE & $6 / 6$ & 0 & 6 \\
\hline B. MOULD BRACHYTHERAPY & $18 / 20$ & 0 & 0 \\
\hline HARD PALATE & \multicolumn{3}{|l}{} \\
\hline ALL SITES(TOTAL) & \multicolumn{3}{|l|}{} \\
\hline
\end{tabular}

Table 3: T3,T4 Lesions Treated By HDR Brachytherapy

\begin{tabular}{|l|c|c|c|}
\hline \multicolumn{4}{|c|}{ A.INTERSTITIAL BRACHYTHERAPY } \\
\hline SITE & T3/T4 & NECROSIS & $\begin{array}{c}\text { NECROSIS } \\
\text { \&FISTULAE }\end{array}$ \\
\hline LIP & $2 / 3$ & 0 & 0 \\
\hline MOBILE TONGUE & $3 / 4$ & 0 & 0 \\
\hline BUCCAL MUCOSA & 0 & 0 & 0 \\
\hline FLOOR OF MOUTH & $3 / 3$ & 0 & 0 \\
\hline TONSILLAR FOSSA & $1 / 1$ & 0 & 1 \\
\hline BASE OF TONGUE & $2 / 3$ & 1 & \\
\hline B. MOULD BRACHYTHERAPY & \multicolumn{3}{|l}{} \\
\hline HARD PALATE & 0 & 1 & 1 \\
\hline ALL SITES(TOTAL) & $11 / 14$ & & \\
\hline
\end{tabular}

Table 4: Patient Charecters For HDR Mould Brachytherapy Of Hard Palate.

\begin{tabular}{|l|l|l|l|l|l|l|}
\hline Patient no. & 1 & 2 & 3 & 4 & 5 & 6 \\
\hline Age(years) & 50 & 62 & 70 & 56 & 60 & 65 \\
\hline T stage & T1 & T1 & T1 & T1 & T1 & T1 \\
\hline H.P Grade & 1 & 3 & 1 & 2 & 1 & 1 \\
\hline Follow up(Years) & 5 & 5 & 3 & 4 & 4 & 5 \\
\hline Response & CR & CR & CR & CR & CR & CR \\
\hline Dose Per \#(Gy) & 3 & 3 & 3 & 3 & 3 & 3 \\
\hline No of fractions & 15 & 15 & 14 & 15 & 14 & 15 \\
\hline Time(days) & 12 & 10 & 14 & 11 & 12 & 12 \\
\hline Mucocitis & confluent & confluent & confluent & Confluent & Confluent & Confluent \\
\hline
\end{tabular}

$\mathrm{CR}=$ Complete Response, H.P = Histo Pathology. Grade 1-well differentiated ,2-Moderaltly differentiated ,3-Poorly differentiated. Gy=Gray 


\section{JMSCR Vol||04||Issue||10||Page 13569-13577||October}

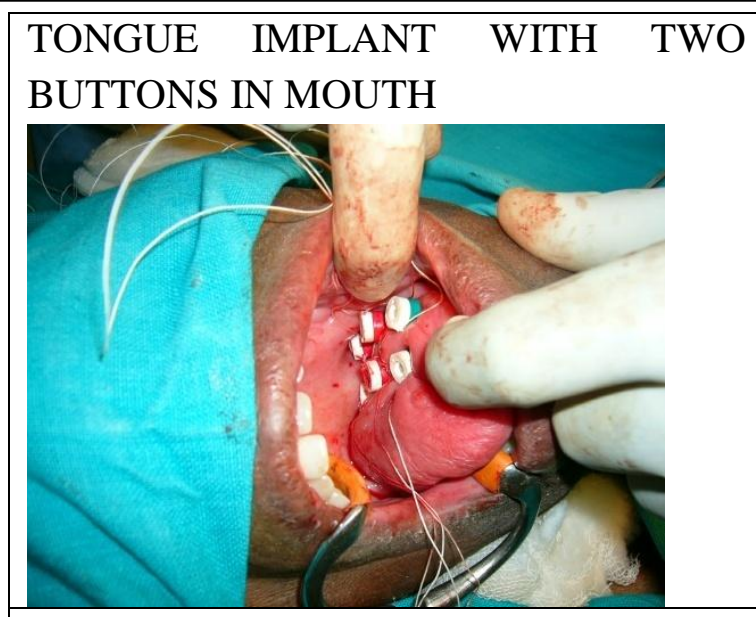

BASE OF TONGUE IMPLANT CHECK FILM

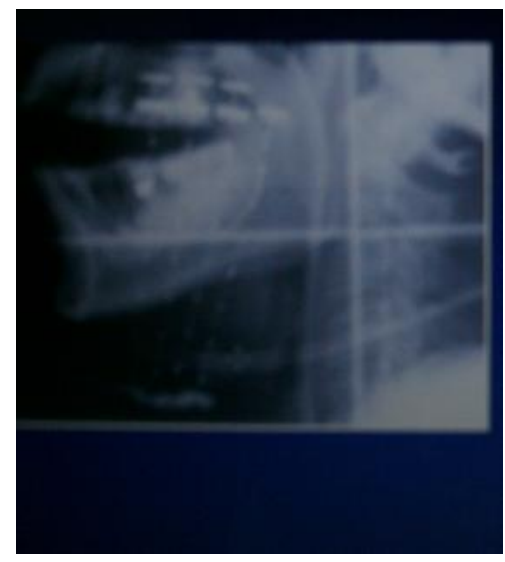

\section{MOULD BRACHY HARD PALATE}

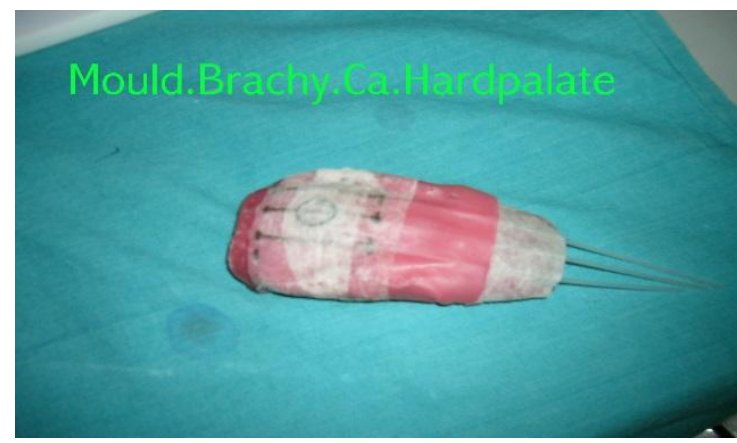

BEFORE BRACHY THERAPY

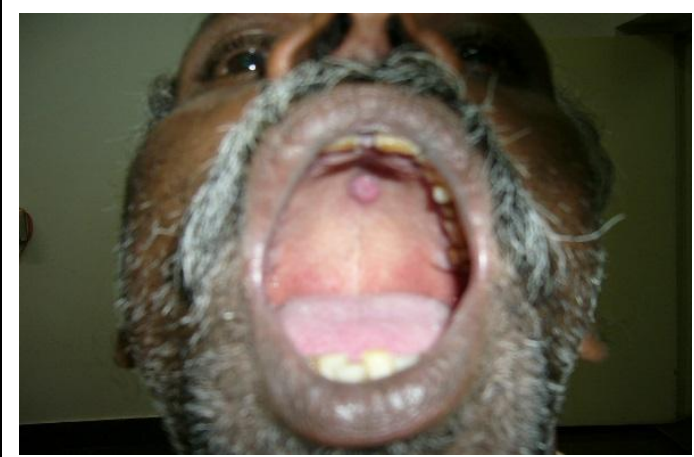

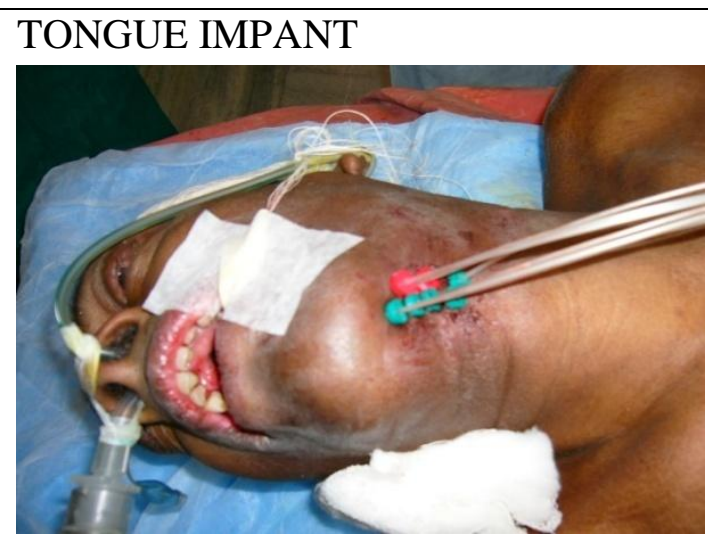

MOULD BRACHY HARD PALATE CHECK FILM

$\boldsymbol{r}$

Mould.Brac fard Hardpalate

\section{ACUTE MUCOSAL REACTION}

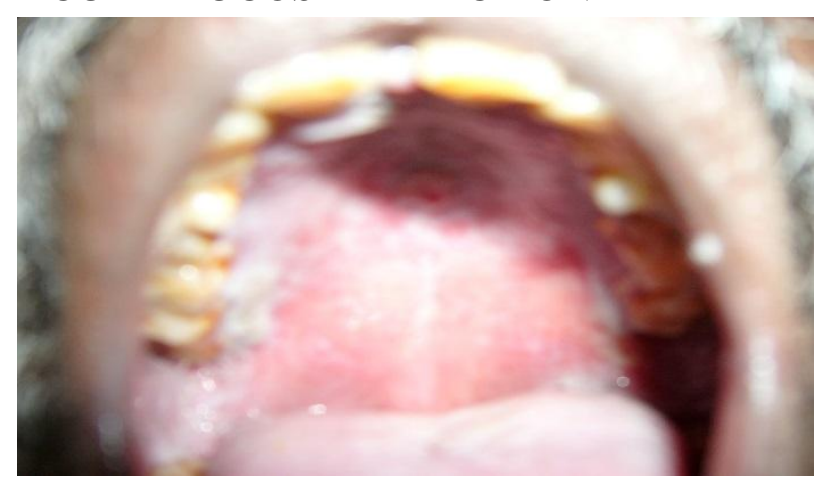

\section{RESPONSE TO TREATMENT}

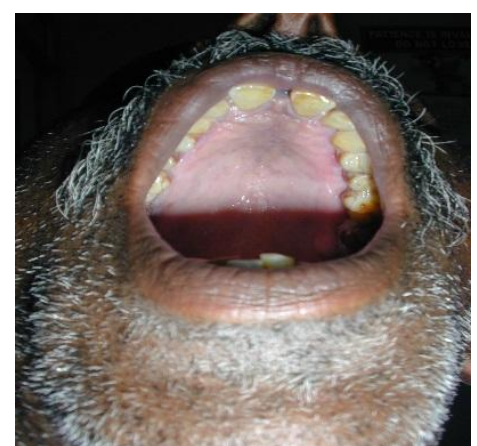




\section{Discussion}

Early cancers of oral cavity can be effectively managed with surgery or radiation. Surgery will be in the form of wide local excision, leading to significant functional or cosmetic problems. Even it is very difficult to achieve negative margin. For early T1, T2 oral cancers Combination of External Beam Radiation plus /minus brachytherapy boost usually in the form of interstitial brachytherapy will have 74 to $92 \%$ control rates ${ }^{11,12 \text { and } 13}$ there is sufficient evidence to prove that Low Dose Rate (LDR) brachytherapy will deliver higher doses of radiation for local control of oropharyngeal cancers and for limiting toxicity ${ }^{14,15,16 \text { and } 17}$. The local control and complication rates were similar with LDR and High Dose Rate (HDR) brachytherapy ${ }^{18,19}$. It is a generally acceptable policy followed in these studies with moderate doses of EBRT and relatively small doses of HDRbrachytherapy to control wide spread lymphatic involvement and implant volume will be more so as to minimize morbidity. In case of locally advanced cancers of head and neck region, the results will be poor, despite escalating EBRT dose up to 70 to $80 \mathrm{~Gy}$ as suggested by Sukovsky and Flecher ${ }^{(22)}$, due to higher incidence of complications and increase in late sequelae of EBRT.

Some authors Richard and Tapley 23 tried to spare contralateral parotid gland by irradiating more lateralized tumors by combination of treatment with photon beam along with high energy electrons. Most of the patients landed up with loco regional failure and complications like osteoradionecrosis, requiring surgical intervention.

The combination of limited dose EBRT and optimal interstitial Ir-192 implant boost in head and neck carcinomas will provide excellent local control rates and most of the patients were spared of delayed sequelae of radiation and mutilating surgeries of functional and esthetic loss ${ }^{(24)}$.

In our series, $90 \%$ of the patients with $\mathrm{T} 1, \mathrm{~T} 2$ lesions, were without loco regional recurrence and without long term complications like soft tissue necrosis and fistula formation and osteoradionecrosis, which were comparable to standard studies by Syed at al ${ }^{(3,24)}$.

We used HDR mould brachytherapy for carcinoma hard palate (T1 lesion) as it is a small volume and clinically and radiologically (CECT) of lymph nodal involvement. In 2004, before initiating treatment, communicated with Subir Nag, regarding evidence of using HDR brachytherapy as a sole modality for dosageschedule ${ }^{(20)}$. In selected patients with early and superficial lesions, the use of surface mould applicators have advantages like avoiding surgical procedure and its sequelae, treatment on outpatient basis, reduction in overall treatment time of 10-14 days as compared to 6-8 weeks when compared to of External Beam Radiation treatment. This option is particularly useful for elderly patients and patients with poor performance status. Follow up examination can detect a local recurrence at the earliest and surgical salvage can be done without much complications as we can limit high dose volume by brachytherapy. Even we can reserve External Beam Radiation as an option for $2^{\text {nd }}$ primaries of head and neck.

In patients with $\mathrm{T} 3, \mathrm{~T} 4$ lesions, $85.71 \%$ were without locoregional recurrence, but one patient with base of tongue region developed local recurrence and complications like soft tissue necrosis and fistulae formation. This may be attributed to the assumption that base of tongue region is more sensitive than the oral tongue and in our series, we are unable to follow the complex implantation technique described by Don R. Goffinet et al ${ }^{(25)}$.

In our series, the results were as comparable to those with standard ones $3,12,13,14,16$ and 17 and complication rates were minimal due to the proper utilization of Computerized Treatment Planning System and optimization ${ }^{7,9}$ and 10 . We did not take up already irradiated patients for brachytherapy .and We did not implanted residual lymph nodes remaining after EBRT electron boost .This may be another reason for minimal complications and 
lesser number of failures even in T3,T4 lesions in our study.

\section{Acknowledgement}

Dr.Subir Nag, Radiation Oncologist, formerly at Ohio state university, USA for guiding me in doing the implant procedures. Dr.Jaya Director, M.N.J.Institute of Oncology \& RCC, Redhills, Hyderabad, India for permitting me to use the data for publication and Dr. Sailaja Elchuri, Associate professor, Sankar Netralaya, Chennai, India, Mr. Jay, USA for his constant help.

\section{Reference}

1. Barrs, D M; Desanto.L.W et al. Squamous cell carcinoma of the tonsil and tongueBase region. Arch Otolaryngeal 105:479485,1979 .

2. Terz, JJ;Richmond. V et al. Carcinoma of tonsillar fossa. Surgery 125:581-590,1967.

3. Syed AMN, Puthawala AA et al. After loading interstitial Implant in head and neck cancer. Arch Otolaryngol 106:541546,1980 .

4. Guix B,Guix JR, Treatmento de los carcinomas cutaneous de losparpados. Arch Otolaryngol1975:35:121-129.

5. Daly NJ, Makissard L, Douches J et al. Technique d' endocurietherapie parfil d'iridium dans leb eiteliomas cutanes. $J$ Radiol Electrol 1978:59:361-364.

6. Ashby MA,Pacella JA,De Groot R,et al. Use of radon mould technique for skin cancers. Results from the Peter Mac Callum Cancer Institute. Br. J.Radiology 1989;62:608-612.

7. Van der Lanrse R. New implementation in VPS Version 10 and itsdifferencesfrom VPS Version 9.11. Nucletron manual. Veenendal. The Netherlands: Nucletron: 1991.

8. Vander Laarse R. Optimization of high dose rate brachytherapy.Activity: Theselectron user's Newsletter 1989;2:14-15.
9. Brock A, Pohlmann S, Prages W. Surface Application for HDR Brachytherapy in thehead and neck region. Selectron Brachytherapy J Suppl 1992:3:22-25.

10. Flynn A. Qualityassurance Checks on a microselectron HDR. Brachytherapy.J 1990;4:112-115

11. chu A,Flecher GH: Incidence and causes of failure to control by irradiation the primary lesions in squamous cell carcinoms of anterior two-thirds of the tongue and floor of mouth. AJR1973;117:502-508.

12. Mendelhall WM, VanCise WS ,Hova I.J,Million RR Analysis of time dose fractionation in Squamous cell carcinoma of the oral tongue and floor of the mouth treated with radiation therapy alone. Int $J$ Radiation oncology Biol Phys 1981:7:1005-1011.

13. Fu KK, Licher A,Galante M: Carcinoma Floor of Mouth : An analysis of treatment results and the sites and causes of failures. Int J Radiation oncology Biol Phys 1976:1 829-837.

14. Goffinet DR,Harrison LB. 192 iridium implantation of the base of tongue. . Int $J$ Radiation oncology Biol Phys 1991: 21;867.

15. Harrison LB, Zelefsky MJ et al .Base of tongue cancers treated with External Beam Radiation plus brachytherapy. Oncologic and functional outcome. Radiology 1992:184;267-270.

16. Puthawala AA, Syed AMN Eads DL et al Limited External Beam Radiation plus interstitial iridium implant in the treatment of Squamous cell carcinoma of the tonsillar region. Int $J$ Radiation oncology Biol Phys 1985;11:1595-1602.

17. Puthawala AA, Syed AMN Eads DL et al Limited External Beam Radiation plus interstitial iridium implant in the treatment of Squamous cell carcinoma of the base of the tongue. A ten year 
experience. Int J Radiation oncology Biol Phys 1988;14:839-848.

18. Dixit S, Baboo HA, Rakesh V, Bhavsar D. Interstitial and High Dose Rate (HDR) brachytherapy in head and neck cancers: Preliminary results.J Brachytherapy Int; 1997;13:363-370.

19. Yu L, Vikram B, Chadha M et al. High Dose Rate Interstitial brachytherapy in head and neck cancers. Endocuriether/ Hypertherm Oncolo1996:12:1-6.

20. Fleming ID, Cooper JS, Henson DE, et al. AJCC Cancer Staging Mannual. $5^{\text {th }}$ edition.Philadelphia: JB Lippincott :1997.p 31-39.

21. Subir Nag, Elmer R. Cano et al. The American Brachytherapy Society Recommendations for HDR brachytherapy for Head-And-Neck carcinoma. . Int $J$ Radiation oncology Biol Phys vol 50:2001;1190-98.

22. Subir Nag, Elmer R. Cano et al .The simplified non looping functional loop technique for HDR brachytherapy. . Int $J$ Radiation oncology Biol Phys 1998;48;339-341.

23. Shukovsky, LJ.; Flecher, GH.: Time-dose and tumor volume relation ships in theirradiation of squamous cell carcinoma of the tonsillar fossa. Radiology 107:621626, 1973.

24. Richard, P ; Tapley , ND.: Lateralized lesions of the oral cavity and oropharynx treated in the part with the electron beam. . Int J Radiation oncology Biol Phys vol 5:461-465, 1979.

25. Ajmel A. Puthawala, A.M.Nisar Syed, et al : Limited external irradiation and Interstitial ${ }^{192}$ Iridium implant in the treatment of squamous cell arcinoma of the tonsillar region. . Int J Radiation oncology Biol Phys vol 11: 1595-1602, 1985.
26. Don R. Goffinet et al. ${ }^{192}$ Iridium pharyngoepiglottic fold interstitial implants. The key to successful treatment of base tongue carcinoma by radiation therapy. Cancer 55: 941-948,1985. 